COMMENTARY

\section{AN AUSTRALIAN LAWYER'S RESPONSE}

Dr Boyle is right in drawing attention to the apparent inconsistency between laws that allow a fetus in utero to be aborted at the mother's will (whether because of abnormality or another reason) but give the law's full protection to a newborn infant, perhaps of the same gestation as the aborted fetus. It makes no difference how disabled the infant is, or how poor the prognosis. The reason for the inconsistency is that the two stages of the infant's development-before birth and after birth-are governed by different legal principles.

While a fetus is in utero, the applicable laws are the criminal law of abortion and the civil law of battery, which here focuses on the mother's direction alone. As Dr Boyle says, the law on abortion in the UK-and also in Australiaenables an abortion to be lawfully performed if continuing the pregnancy would present a real risk to the mother's life, or her physical and mental health; and, additionally, in some jurisdictions like the UK, for serious fetal abnormality: see Abortion Act 1967 (UK), ${ }^{1}$ which includes risks to "existing children" as well as to the mother. ${ }^{2}$ Recent changes to the criminal law in the Australian Capital Territory and Western Australia have gone further and abortion is now lawful in those jurisdictions, simply on the informed request of the mother.

In jurisdictions that do not have a specific provision allowing abortion on the grounds of fetal abnormality, doctors have inferred that having a child with a serious abnormality would constitute a threat to the mother's life or health, again focussing on the mother. The concept of harm to the mother's health has been interpreted by the courts to include harm during pregnancy and delivery and also after the birth. ${ }^{4}$ This might take account of difficulties in raising a child with a serious disability but is assessed by reference to the mother. Thus abortion is lawful well into pregnancy (up to 24 weeks in the $\mathrm{UK}^{2}$ ) based on the mother's life or health, but subject to the law of child destruction, where such an offence is provided by statute (as in the UK: see below).

The mother is the only person whose consent is relevant for abortion. The civil law of battery prevents any "invasion" of the body of a competent adult patient, so no one can compel a woman to have an abortion-or to have any prenatal tests or treatment for the fetus that she chooses not to have. But if she does decide to have an abortion, her consent is sufficient legal authority for it to be done, provided that the abortion is not unlawful under the criminal law. No one can prevent her having an abortion, including the baby's father: see AttorneyGeneral (Queensland) (ex rel Kerr) v T (1983) I Qd R 404; (1983) 46 ALR 285 (HCA); and $F \vee F$ (1989) FLC 92-03, in which biological fathers were refused injunctions to prevent abortions being carried out. Also, a mother cannot be compelled to have an abortion on medical advice-for example, if her child has no prospect of living beyond a short period; the decision is hers alone.

This means that an infant in utero has very limited legal rights. The fetus certainly does not have an enforceable "right to life" because, as noted earlier, no one can intervene to prevent the mother having an abortion, even well into in the pregnancy. The only protection the fetus has against being aborted is a statutory time limit on lawful abortions, like the 24 week limit in the Abortion Act ${ }^{2}$; or the statutory offence of "child destruction". Where such an offence exists, "child destruction" means destroying the life of a child capable of being born alive. ${ }^{5}$ Other Australians jurisdictions have a similar offence. It is no defence that the mother wishes the pregnancy to be terminated, or that the child has a seriously disability. The only defence is acting to save the mother's life. In South Australia, this is explicit (s 82A(7) $)^{5}$; in other jurisdictions, it is implicit (that is, implied from the word "unlawfully" in the wording of the offence). The main point for present purposes is that the sole determinant of the legality of terminating a pregnancy is risk to the mother's life and, in the case of abortion, also her physical or mental health.

In contrast, once a child has been born, the child is protected by the criminal law of homicide, with its focus not on the mother, but on the child. However impaired the child and however bleak the child's prospects, it is a criminal offence to deliberately cause or hasten the child's death. This does not mean that the child's life must be preserved at all costs. It is lawful not to offer the full range of treatment, and treatment may lawfully be withheld or withdrawn if it is "futile" (a term of indefinite meaning). ${ }^{6}$ Also, the infant may be given whatever pain relief is necessary to alleviate pain and distress, even if that hastens death. Provided the doctors' primary intention is to alleviate pain, the secondary effect ("double effect") of hastening death does not make this homicide, ${ }^{7}$ but the doctors may not lawfully hasten the child's death by a positive act.

The process of decision making after a child has been born is governed by the civil law of battery in the same way as the law relating to the mother's consent to an abortion. But, whereas a competent adult patient can lawfully consent to (or refuse) a medical procedure even if that seems not to be in the patient's best interests, parental powers to make medical decisions for their children are constrained by laws that protect the welfare of the child. Parents (normally either parent) have authority to consent to treatment for their child, or to refuse it (there are exceptions for emergencies and cases where parents cannot be found). However, parents cannot require a particular treatment for their child (in the same way that other patients can not demand particular treatments). ${ }^{8}$ Nor can they refuse treatment that is in a child's best interests. If they purport to refuse in such cases, any person can apply to a court for an order overriding the parents' refusal or appointing another person to consent in place of the parents. Courts have generally been conservative in such cases $^{9}$ but in one English case, the court was persuaded by the arguments of the mother of a baby born with life threatening liver disease that a liver transplant would not be in his best interests. ${ }^{10}$ This was because of the mother's deep seated concern as to the benefits to her son of the major invasive surgery and postoperative treatment, the dangers of failure long term as well as short term, the possibility of the need for future transplants, the likely length of life, and the effect upon her son of all these concerns. ${ }^{11}$

Where parents refuse consent for treatment that they do not consider in their child's best interests, it is common for doctors and other health professionals to continue treatment pending a court order authorising that course (as Boyle says in his text to notes 25 and 26). I know of no case in which parents have been successful in civil proceedings for battery in such circumstances. Not only would this be an unsympathetic action; it is hard to imagine what damages might be awarded.

In summary therefore, the law approaches abortion from the viewpoint of the mother-it is lawful if her life or health would be seriously at risk if the pregnancy continued, (including by the birth of a child with a serious abnormality); and if she provides informed consent. Once the child is born (or capable of being born alive, in jurisdictions that have an offence of child destruction), the law focuses on the welfare of the child and the parents have power to consent to (or refuse) procedures only if that is in the child's best interests. 
This has the result identified in Dr Boyle's paper-that the same child may have different legal protection, depending on whether the child is still in the mother's womb or has been prematurely delivered. However, I am not totally persuaded by Dr Boyle's suggestion that a court might allow parents to withhold treatment against medical advice for a 25 week old neonate on the grounds that the child's chances of thriving, or even of survival, were comparable with those in Re $T$ (the liver transplant case). Courts have traditionally been much more conservative in considering applications to withhold treatment from critically ill neonates than from older patients. The case of Re T regards only one authority and the circumstances in that case were unusual (the parents were health professionals and well educated about the child's condition; they did not live permanently in England; and the medical evidence was not unanimous). On the other hand, the court did acknowledge in that case that the child's interests were very much connected with the mother's, which may bring closer together the competing interests in the law of abortion, child destruction, and homicide.
Faculty of Law, University of Melbourne, Parkville, Melbourne, Victoria Australia; I.skene@unimelb.edu.au

\section{REFERENCES}

1 Abortion Act 1967 (UK) s 1 (1). Norwich, UK: Her Majesty's Stationery Office. 2 Abortion Act 1967 (UK) s 1(1)(a). Norwich, UK: Her Majesty's Stationery Office.

3 See Crimes (Abolition of Abortion) Act 2002 (ACT) s 3; Criminal Code 1913 (WA) s 199; Health Act 1911 (WA) s 334.

4 CES v Superclinics Australia Pty Ltd (1995) 38 NSWLR 47; (1995) Aust Torts Reports 81-360 (NSW CA); see also Abortion Act 1967 (UK) s 1(2).

5 For example, in the Australian jurisdictions that have followed the Infant Life (Preservation) Act 1929 (UK), Victoria and South Australia: Crimes Act 1958 (Vic) s 10; Criminal Law Consolidation Act 1935 (SA) s 82A(7)-(8).

6 See Airedale National Health Service v Bland (1993) AC 789; (1993) I All ER 821 (HL); Re J (a minor) (wardship: medical treatment) (1990) 3 All ER 930 (CA); Re J (a minor) (wardship: medical treatment) (1991) Fam 33; (1990) 3 All ER 930 (CA); A National Health Service v D (2000) 55 BMLR 19 (HC).

7 See R v Adams (1957) Crim Law Rev 365 (CCC)

8 See R v Cambridge Health Authority; Ex parte B (1995) 2 All ER 129 (CA).

9 Manning J. Parental refusal of life-prolonging medical treatment for children: A report from New Zealand. J Law Med 2001;9:269-71.

10 See Re T (wardship: medical treatment) (1987) 1 All ER 906 (CA) (discussed by Boyle, text to note 17).

11 Butler-Sloss $\sqcup$ at 915.

\section{BOOK REVIEW}

\section{Medical Ethics and Law: the Core Curriculum}

T Hope, J Savulescu, J Hendrick. Churchil Livingstone, 2003, £15.99, pp 222. ISBN 0443062552

This is a slim, user friendly volume designed to introduce medical students and practicing clinicians to some basic issues of medical law and ethics, as well as to the ways in which lawyers and philosophers characteristically think. The book is divided into two parts: the first adumbrates the main ethical theories, some central ethical concepts, the role of law in society, and the English legal system (with the first of many comparative glances at Scotland); the second part comprises chapters about key issues such as "consent", "reproductive medicine", and "mental health".

This integration of ethics and law into such an accessible and tidy package is the main strength of the book. More weighty tomes have aimed for the same integration (the recent new editions of Montgomery's and Brazier's books, for example), but their scholarly density makes them more appropriate for reference than overview. The integration is important because there will always be certain students and practitioners who do not see the point of academic ethics, whereas these days no one can afford to ignore the law. The gaps and ambiguities in the law can then provide the framework for meaningful ethical discussion. Even without the ethics, however, the book's discussions of the law are sufficiently subtle to provide a basic understanding of the law in action: the large amount of uncertainty that remains, especially in medical law; the problems of applying and interpreting precedents and statutes, and the conflicting assumptions and intuitions that underlie the whole business.

The book has two other strengths. First, the referencing: there are lengthy sections on "further reading" at the end of each chapter, there are useful websites sprinkled throughout, and a handy annotated appendix of websites. Given how quickly the relevant law, policy, and technology are changing, these website references are especially valuable. A few more annotations to the references would have helped to guide the beginning reader, however. The second main strength is the overall clarity of the book; the issues discussed are enormously complex, and the authors have done very well to lay out the main components of those issues without over simplifying: the central problem to each issue remains at the forefront, thus inviting the reader's engagement. I also liked the layout, with certain self-contained questions or cases given a separate treatment in a special box. Jargon is introduced gradually, and kept to a minimum.

The book's title refers to the Core Curriculum in medical law and ethics, a document compiled by a large number of people for this journal six years ago ( $J$ Med Ethics 1998;24:147-8). Insofar as this was a statement of consensus about the content and approach to be used in the teaching of ethics in medical schools, then this book reflects that consensus faithfully. My main criticism of the book would be about its selection of issues in part two, and therefore my criticism is a more general one about the core Curriculum.

Given the target readership and breadth of their clinical interests, I suggest that some of the issues in the Core Curriculum are simply too narrow: genetics, organ donation, and some aspects of reproductive medicine and mental health, however fascinating in their own right, all involve highly specialised clinical training, and will therefore not be encountered by the average clinician and student as often as the other issues; whereas the chapters on consent and confidentiality are of obviously wide application. (I am also unsure whether there are enough active researchers among the target readership to justify giving a whole chapter to "research ethics", rather than including it as a subchapter of "consent".)

In place of the above "narrow" topics, I suggest that certain ethically charged issues affecting almost all clinicians deserve more systematic and extended treatment in an introductory book like this: whistle blowing, truth telling, trust, power, and authority, Good Samaritanism, the symbolic function of the law in a society, the ethics of NHS bureaucracy (targets, accountability, and so on), the patient's responsibility for their own health, the contrast between good ethical judgement and good clinical judgement, defensive medicine and patient litigiousness, the clinician's role as psychotherapist and social worker.

There is a very important chapter in part one on the relationship and communication between doctor and patient, and some of the above questions are mentioned briefly there. But I fear this section is a bit too short, and does not take enough account of the patient's wider relationships with her family and community (although there is a passing mention of communitarian theory in the chapter introducing the various ethical theories).

Perhaps more controversially, I think the book should also have built on its important discussions of the fact/value distinction and of the emotions (both very welcome) to include a critique of the mechanist (in the philosophical sense) assumptions underlying all-pervasive scientific medicine: the thought that the body is no more than a complex machine, and that, for example, a mastectomy is no more than the removal of useless flesh. Arguing against materialism is more than just taking the patient's concerns about their illness seriously: it is about the very purpose of medicine in society.

C Cowley c.cowley@uea.ac.uk 